\title{
Telomerase expression and proliferative activity suggest a stem cell role for thyroid solid cell nests
}

\author{
Ana Preto $^{1, *}$, José Cameselle-Teijeiro ${ }^{2, *}$, Julio Moldes-Boullosa ${ }^{2}$, Paula Soares ${ }^{1,5}$, \\ Jorge F Cameselle-Teijeiro ${ }^{3}$, Paula Silva ${ }^{1}$, Jorge S Reis-Filho ${ }^{1,4}$, Rosa M Reyes-Santías ${ }^{2}$, \\ Natividad Alfonsín-Barreiro ${ }^{6}$, Jerónimo Forteza ${ }^{2}$ and Manuel Sobrinho-Simões ${ }^{1,5,7}$ \\ ${ }^{1}$ Institute of Molecular Pathology and Immunology, University of Porto, Porto, Portugal; ${ }^{2}$ Department of \\ Pathology, Hospital Clínico Universitario, University of Santiago de Compostela, Santiago de Compostela, \\ Spain; ${ }^{3}$ Department of Pathology, Hospital Xeral-Cíes, Vigo, Spain; ${ }^{4}$ The Breakthrough Toby Robins Breast \\ Cancer Research Centre, Institute of Cancer Research Mary-Jean Mitchell, Chester Beatty Laboratories, \\ London, UK; ${ }^{5}$ Medical Faculty of the University of Porto, Porto, Portugal; ${ }^{6}$ Department of Pathology, Hospital \\ do Meixoeiro, Vigo, Spain and ${ }^{7}$ Hospital de S. João, Porto, Portugal
}

\begin{abstract}
Solid cell nests of the human thyroid gland are composed of main cells and C cells. In order to investigate the putative stem cell nature of the role for solid cell nests, we evaluated the histological features, and the immunohistochemical expression of p63, bcl-2, telomerase catalytic subunit, and two proliferative markers (Ki-67 and minichromosome maintenance protein 2), in a series of 24 cases of solid cell nests. Proliferative indices were determined in (a) solid cell nests, (b) thyroid follicular cells in the vicinity of solid cell nests within a low-power field, and (c) distant thyroid tissue, at a distance of at least three low-power fields from solid cell nests. In 15 cases of solid cell nests (62.5\%), mixed follicles were observed; papillary formations were observed in four cases (16.6\%), and ciliated cells were observed in the lining of microcysts associated with two cases (8.3\%). Salivary gland-type tissue, cartilage islands, adipose and fibrous tissues, and small nerves were also associated with some cases of solid cell nests. We observed that the main cells of the solid cell nests express consistently telomerase, although at lower levels than p63, and show strong cytoplasmic immunoreactivity for bcl-2, which is associated with an increased differentiation potential. We also observed that despite their relative low proliferative index, main cells of the solid cell nests display higher proliferation than follicular cells in the vicinity and follicular cells in more distant thyroid tissue. We conclude that main cells of the solid cell nests apparently harbor the minimal properties of a stem cell phenotype (capacity for both self-renewal, conferred by telomerase activity, and differentiation to one or more than one type of specialized cells, given by the high expression of $\mathrm{p} 63$ and bcl-2) and may thus represent a pool of stem cells of the adult thyroid.

Modern Pathology (2004) 17, 819-826, advance online publication, 26 March 2004; doi:10.1038/modpathol.3800124
\end{abstract}

Keywords: solid cell nests; stem cells; telomerase; p63; bcl-2; Ki-67; MCM2; ultimobranchial body

Solid cell nests of the human thyroid gland, usually considered as the embryonic remnants of the ultimobranchial body, are composed of two types of cells that are referred to as 'main cells' and ' $\mathrm{C}$ cells'. ${ }^{1}$ Main cells, which account for a major proportion of solid cell nests, are polygonal to elongated cells with centrally located, oval to fusi-

Correspondence: Dr J Cameselle-Teijeiro, MD, PhD, Department of Pathology, Hospital Clínico Universitario, Choupana s/n, 15706

Santiago de Compostela, Spain.

E-mail: apjocame@usc.es

*AP and JC-T contributed equally to the present study.

Received 17 December 2003; revised 15 January 2004; accepted 18

January 2004; published online 26 March 2004 form nuclei having uneven nuclear envelopes that include occasional grooves; these cells show deeply eosinophilic cytoplasm with squamoid features but lacking intercellular bridges. ${ }^{1}$

p63 is a member of the p53 tumor-suppressor gene family with structural homology to p53 that is involved in survival and differentiation of reserve/ stem cells in different epithelia. ${ }^{2-4}$ It has been advanced that p63 plays a role in triggering the differentiation of some specific cell lineages. ${ }^{2-7} \mathrm{We}$ have previously shown that p63 and basal keratins are restricted to the main cells, being negative in the $\mathrm{C}$ cells and in other thyroid structures, and advanced that the main cells of the solid cell nests display a basal/stem cell phenotype. ${ }^{8}$ Bcl-2 
overexpression has also been associated with stem cells. ${ }^{9}$ However, the precise definition of a stem cell is still a controversial issue; it is generally accepted that stem cells exhibit extensive self-renewal capacity, differentiation potential and may exist in a mitotically quiescent form, but these properties are not always present in all the stem cells of human tissues. ${ }^{10}$

Somatic cells have a limited replicative potential in vitro due to the progressive loss of the telomeres cap in each cell division. ${ }^{11,12}$ The shortening of the telomeres can be overcome by the reactivation of telomerase, a ribonucleoprotein enzyme composed of two subunits: the human telomerase RNA template subunit (hTR) constitutively expressed, and a catalytic subunit, the human telomerase reverse transcriptase (hTERT), responsible for the activity of the enzyme in the elongation and maintenance of the protective telomere structure at the end of the human chromosomes. Long-lived cell populations such as the germline and stem cells, which need a high self-renewal potential, can circumvent the telomeric barrier acquiring unlimited proliferation capability by expressing telomerase. ${ }^{13}$ In contrast to its presence in $80-90 \%$ of malignant tumors, ${ }^{14-16}$ telomerase activity is undetectable in most normal cells and tissues. ${ }^{17}$ The restoration of telomerase activity in human cells may confer increased replicative lifespan without eliciting a cancer-associated phenotype. ${ }^{18-20}$

Some stem cells may divide rarely, like the stem cells of the skin, whereas others, like the intestinal crypt stem cells, divide frequently. ${ }^{10}$ Several proliferation markers have been used to identify cycling cells, namely Ki-67, ${ }^{21}$ a nuclear antigen expressed in proliferating cells and, more recently, the human minichromosome maintenance protein 2, (MCM2) a protein that plays a role in DNA replication and actively participates in cell cycle regulation as part of minichromosome maintenance complexes. ${ }^{22}$

In order to define the self-renewal potential and the proliferation rate of the main cells of the solid cell nests, we investigated the histological features, and the immunohistochemical expression of p63, bcl-2, hTERT, Ki-67, and MCM2 in a series of 24 solid cell nests of the thyroid.

\section{Material and methods}

Formalin-fixed, paraffin-embedded tissues from 24 cases of thyroid pathology with solid cell nests were retrieved from the files of the Hospital Clínico Universitario, Santiago de Compostela, Spain. All cases were reviewed by three of the authors (AP, JC$\mathrm{T}$, and MS-S) and the clinical data were obtained either from pathology reports or from patient charts. The clinical data of the patients and the major thyroid lesions are summarized in Table 1.

Immunohistochemical analysis: In every case, $4 \mu \mathrm{m}$ serial histological sections were cut and mounted in silane-coated slides. Immunohistochemistry using the streptavidin-biotin-peroxidase complex technique was performed as described elsewhere, ${ }^{23}$ using antibodies raised against p63 (clone 4A4, dilution 1:150 - 1h, Neomarkers, Freemont, CA, USA), bcl-2 (clone 124, dilution $1: 10$ - $30 \mathrm{~min}$, Dako), MCM2 (clone CRCT2.1, dilution 1:25 - 1h, Novocastra Laboratories, UK) and MIB-1 (clone Ki-67, dilution 1:50 - $30 \mathrm{~min}$, Dako, Glostrup, Denmark), calcitonin (Polyclonal, BioGenex, San Ramón, CA, 1:200) and the catalytic subunit of telomerase (hTERT) (clone 44F12, dilution 1:25 - $1 \mathrm{~h}$, Novocastra Laboratories, UK). For the telomerase immunohistochemical assay, we included as telomerase-positive controls tonsil (as indicated by the commercial vendor to validate the antibody) and colon (the basal cells of the intestinal crypts are telomerase positive); as an internal negative control, we used the follicular thyroid cells distant from solid cell nests. Heat-induced antigen retrieval using antigen retrieval solution (Dako) was performed by $20 \mathrm{~min}$ incubation in a water bath at $98^{\circ} \mathrm{C}$. Negative and positive controls were concurrently run for all antibodies with satisfactory results. Cells were considered positive for telomerase whenever nuclear staining was observed. Cells were considered positive for MIB-1 and MCM2 when diffuse or dot-like nuclear staining was observed regardless of the intensity of the staining; only nuclear immunoreactivity was considered specific. The number of positive cells was counted by two different observers (AP and JC-T) independently. Whenever necessary, a consensus was reached using a double-headed microscope. Stromal and/or lymphoid staining were excluded from the counting process. The percentages of positively staining nuclei were obtained in each case by counting at least 500 epithelial cells at high-power field $(\times 400)$ in three different spots: solid cell nests, follicular epithelial cells in the vicinity of solid cell nests, and follicular cells at a distance of at least three lowpower fields from solid cell nests. The distinction between main cells and C cells from the solid cell nests was based on the calcitonin staining in serial sections, since as previously shown only C cells stain for calcitonin. ${ }^{1,8}$ Three cases with solid cell nests containing less than 500 epithelial cells were previously excluded from this study. Data were analyzed by Fredman's test and the Bonferroni correction for multiple comparisons. All values were presented as mean \pm s.d., and two results were considered to be significantly different when $P<0.05$.

\section{Results}

\section{Clinical Profiles and Pathological Findings}

Of the 24 patients, eight (33.3\%) were male and 16 $(66.6 \%)$ female. Ages ranged from 28 to 89 years (average, 54 years; s.d., 18.4 years). Multinodular 
Table 1 Clinicopathological parameters and proliferation indexes in 24 cases with solid cell nests

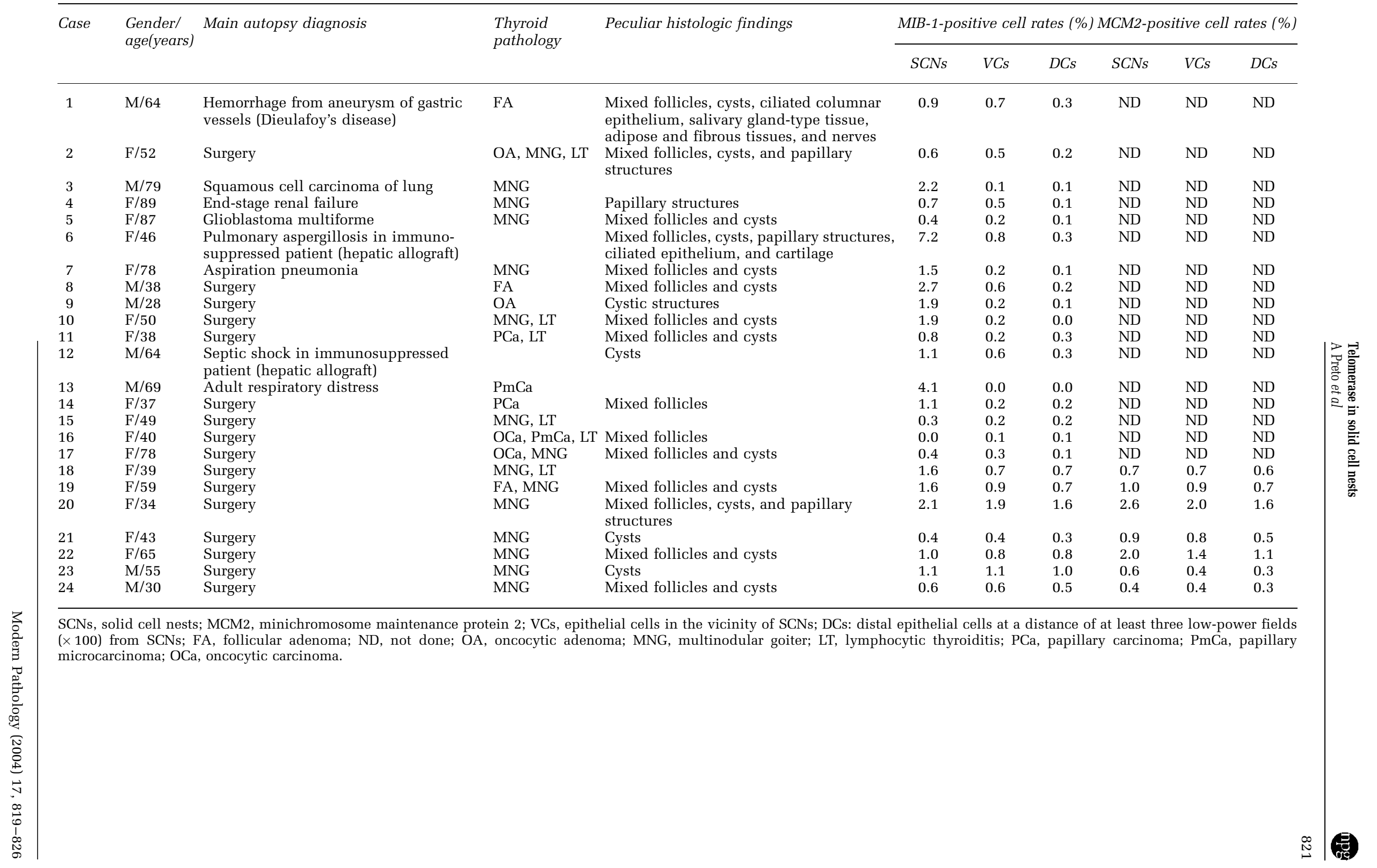


goiter was found in 15 cases (62.5\%), lymphocytic thyroiditis in six (25\%), papillary carcinoma in four (16.6\%), Hürthle cell (oncocytic) carcinoma in two $(8.3 \%)$, and Hürthle cell (oncocytic) adenoma in two $(8.3 \%)$.

Table 1 summarizes the major clinical data, including causes of death in the autopsied patients, as well as histological and immunohistochemical features.

The solid cell nests were single or multiple foci of squamoid cluster cells delineated by a basement membrane, and were composed of a dual cell population of main cells and C cells as previously described $^{1,8}$ (Figure 1). The main cells showed frequent nuclear grooving, but only a single nuclear pseudoinclusion was found in one case (case 9). Intermingled with main cells, and mainly confined to the periphery of the cell nests, the population of $\mathrm{C}$ cells, numerically less conspicuous, was characterized by clear or empty cytoplasm and round nuclei (Figure 1b). In 15 cases (62.5\%), the solid cell nests contained mixed follicles - structures lined by

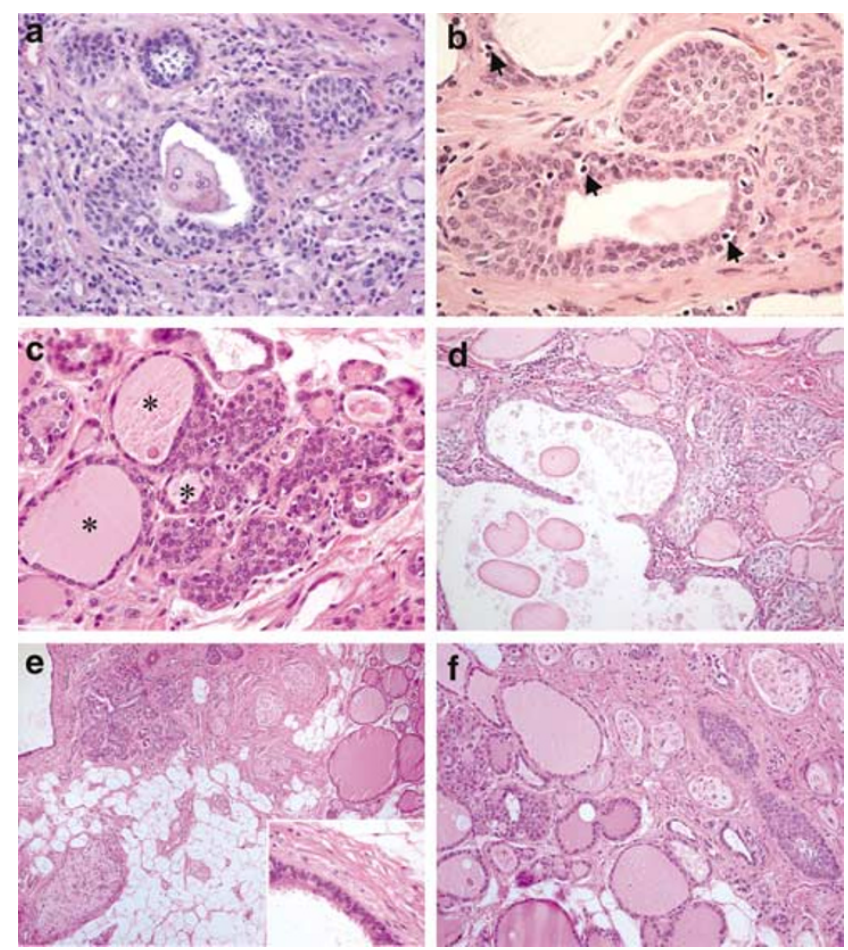

Figure 1 Solid cell nests of the human thyroid gland. (a) Solid cell nests with associated microcystic formation. A dense colloidlike material fills the lumen of the cyst. (b) Solid cell nests also contain a less conspicuous population of C cells (arrows) characterized by clear or empty cytoplasm. (c) Note the squamoid appearance of the main cells and the mixed follicles (asterisks). (d) Microcysts and papillary structures are observed in association with the solid cell nests. (e) Cysts lined by a ciliated epithelium (inset, $\times 400$ ), salivary gland-type tissue, fibrous tissue, mature fat, and small nerves are found associated to solid cell nests in case 1. (f) Nerves are observed in intimate association with the solid cell nests in the same case. (a)-(f) hematoxylin and eosin; (a)-(c) original magnification $\times 400$; (d) and (f) $\times 200$; (e) $\times 100$. main cells and follicular epithelium with colloid and/or clumps of eosinophilic material in the lumen (Table 1) (Figure 1c). Microcysts were observed in 16 cases (66.6\%) (Figure 1a). Cases 1 and 6 showed microcysts lined by a ciliated epithelium (Figure 1e). Papillary formations were observed in cases 2 , 4, 6, and 20 (Figure 1d). A cartilage island was found in intimate contact with the solid cell nests in case 6 , and salivary gland-type tissue, fibrous tissue, mature fat, and small nerves were associated with solid cell nests in case 1 (Figure 1e and f). No continuity between the thyroid neoplasms and the solid cell nests was observed in any case.

\section{Immunohistochemical Analysis}

\section{hTERT}

Telomerase immunostaining was observed in the main cells of the solid cell nests; the expression pattern is similar to that of p63 but with lower staining intensity (Figure 2a and b). C cells did not express telomerase in any case; the cases with areas of lymphocytic thyroiditis showed high telomerase immunoreactivity in the lymphocyte nuclei as has been previously described. ${ }^{13}$ Lymphocyte immunoexpression was thus used as an internal positive control. Telomerase immunoexpression was not restricted to the main cells of solid cell nests; faint immunoreactivity was also detected in scarce follicular cells in the vicinity of some of the solid cell nests.

\section{p63 and bcl-2}

As previously demonstrated, p63 immunostaining was restricted to the main cells of the solid cell nests, ${ }^{8}$ strongly decorating their nuclei (Figure 2c). The $\mathrm{C}$ cells of the solid cell nests were negative for p63 in every case. In adjacent thyroid tissue, p63 immunoreactivity was not detected in normal or hyperplastic follicular cells, nor in C cells.

In all the cases, main cells of solid cell nests showed strong cytoplasmic reactivity for bcl-2 (Figure 2d); less intense immunoreactivity was also observed in most follicular cells regardless of the vicinity of solid cell nests.

\section{$M I B-1$ and MCM2}

The values of MIB-1 labeling for each case $(n=24)$ are summarized in Table 1. The highest proliferation index assessed by MIB-1 was found in the main cells of solid cell nests $(1.5 \%$, s.d. \pm 1.5$)$, in contrast to the vicinity cells $(0.5 \%$, s.d. \pm 0.4$)$ and follicular cells in more distant thyroid tissue $(0.3 \%$, s.d. \pm 0.4$)$; in the pairwise comparisons, a statistically significant difference $(P<0.05)$ was found between main cells and cells at a greater distance.

Table 1 also summarizes the percentages of positive nuclei found in solid cell nests using both proliferative markers $(n=7)$. No significant difference was found between levels of expression of 


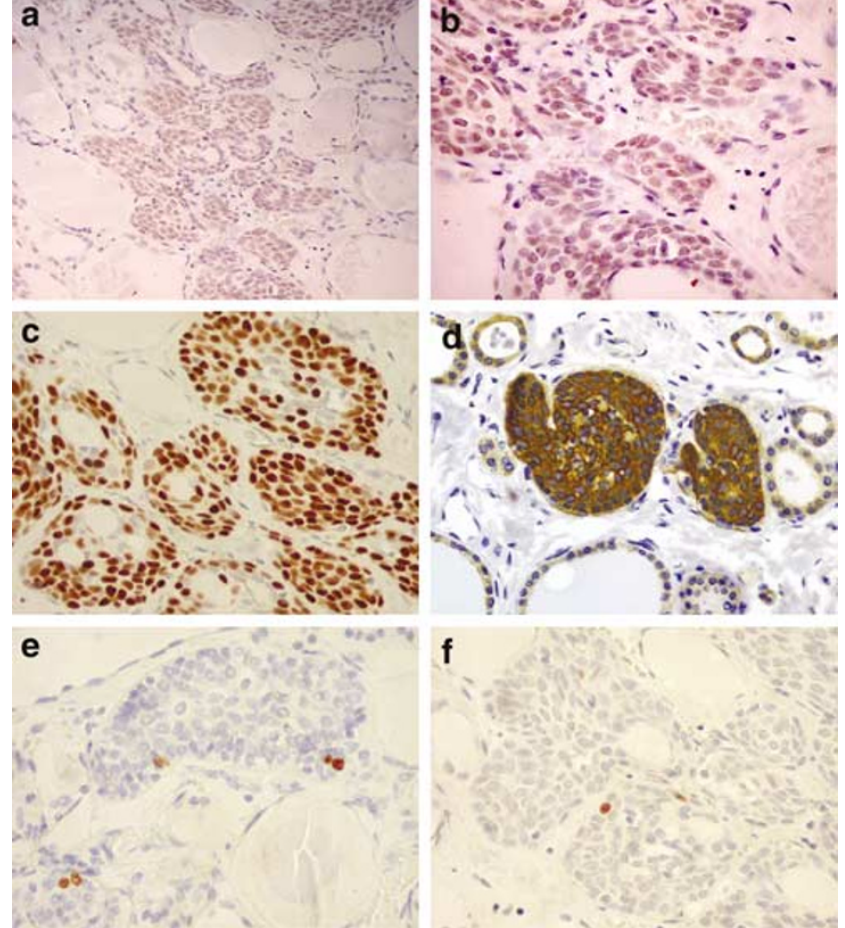

Figure 2 Solid cell nests of the human thyroid gland. (a) and (b) Telomerase expression in the nuclei of main cells; also note a faint immunoreactivity in the thyroid follicular cells adjacent to solid cell nests. (c) Strong nuclear immunoexpression for p63 in the main cells of solid cell nests. (d) Strong cytoplasmic reactivity for bcl-2 was also observed in solid cell nests. Proliferation markers in solid cell nests: MIB-1 (e) and human minichromosome maintenance protein 2 (f) immunoreactivity confined to the nuclei of main cells of solid cell nests. (a)-(f) Streptavidinbiotin; (a) original magnification $\times 100$; $(\mathbf{b})-(\mathbf{f}) \times 400$.

MIB-1 and MCM2 $(P=0.895)$ (Figure 2e and $f)$. The proliferation indices in the solid cell nests $(1.2 \%$, s.d. \pm 0.6 for MIB- 1 and $1.2 \%$, s.d. \pm 0.8 for MCM2) were higher than in follicular cells distant from solid cell nests $(0.8 \%$, s.d. \pm 0.4 for MIB- 1 and 0.7 s.d. \pm 0.5 for MCM2), with a statistical significance difference of $P=0.03$ for MIB-1 and $P=0.02$ for MCM2. The proliferation rates of follicular cells in the vicinity of SCN $(0.9 \%$, s.d. \pm 0.5 for MIB- 1 and $0.9 \%$, s.d. \pm 0.6 for MCM2) were not significantly different from those of solid cell nests. We did not observe immunoreactivity for any of the proliferation markers in the nuclei of $\mathrm{C}$ cells.

\section{Discussion}

The ultimobranchial body origin of solid cell nests was first proposed by Erdheim in $1904,{ }^{24}$ and marked similarities were pointed out between the solid cell nests and the ultimobranchial body of the rat, ${ }^{25}$ dog, ${ }^{26}$ and bull. ${ }^{27}$ The unusual association of solid cell nests with thymic, ${ }^{28-31}$ parathyroid, ${ }^{28,29}$ adipose, ${ }^{1,30}$ fibrous, ${ }^{32}$ cartilaginous, ${ }^{1,32}$ and salivary gland-type tissues $^{32}$ has been documented, and together with the production of mucins $s^{1,28,33,34}$ reinforces the endodermal, ultimobranchial body origin of solid cell nests. The topographic distribution of solid cell nests in the thyroid gland, their association with $\mathrm{C}$ cells and different tissues related to branchial structures, and the presence of solid cell nests in some piriform sinus fistula (which are also considered as remnants related to the ultimobranchial body) ${ }^{35}$ further support the existence of a relationship between solid cell nests and the ultimobranchial body. To the best of our knowledge, the presence of neural fibers in relation with solid cell nests has not been previously reported. The association of solid cell nests with nerves and adult tissues derived from other germinal layers in case 1 of the present series fits with the diagnosis of a (small) teratoma, and indicates that main cells may serve as multipotential stem cells.

Pueblitz et $a l^{36}$ found thyroid C cells in the autopsies of children with the DiGeorge anomaly. The fact that $\mathrm{C}$ cells were present in a high percentage of cases, even in those exhibiting all the stigmata of the DiGeorge anomaly, raised the possibility of an additional source of $C$ cells for the thyroid. ${ }^{36,37}$ Williams et $a l^{38}$ found cystic structures with glandular nodules composed of $\mathrm{C}$ cells (positive for calcitonin and calcitonin gene-related peptide) intermixed with follicles (immunoreactive for thyroglobulin) in the lateral neck of four cases of maldescend of the medial thyroid anlage. On the basis of these observations, they concluded that the ultimobranchial contributes both $\mathrm{C}$ cells and follicular cells to the thyroid gland. ${ }^{38}$

The main cells of solid cell nests are negative for markers of terminal differentiation such as thyroglobulin, ${ }^{1,8,34}$ thyroid transcription factor (TTF-1), ${ }^{8}$ calcitonin, ${ }^{1,8,34}$ and calcitonin gene-related peptide. ${ }^{1}$ In mixed follicles, the continuity between main cells and follicular cells suggests that the latter are produced through a maturation process of the former. ${ }^{1,8}$

Until now, no well-defined stem cell population has been identified in the thyroid gland. Our group suggested a few years ago that the main cells of solid cell nests might be the multipotential cells that could contribute to the histogenesis of $\mathrm{C}$ cells and follicular cells, as well as to some thyroid tumors. ${ }^{39}$ This claim was based on the wide spectrum of differentiation found in solid cell nests ${ }^{1,34,39}$ and has found additional support on the finding of p63 immunoreactivity restricted to the main cells of solid cell nests. ${ }^{8,40}$ The results obtained in the present study confirm and extend those we and others had previously reported on the high level of expression of p63 in the main cells of solid cell nests. ${ }^{8,40}$ We found overexpression of bcl-2 in the main cells of solid cell nests. It has been shown that bcl-2 protein expands the life of epithelial cells capable of differentiation and enables differentiation and morphogenesis to occur. ${ }^{9}$ The increased expression of bcl-2 in solid cell nests is thus in 
agreement with the embryonal/noncommited phenotype of stem cells.

There is still ambiguity about what exactly constitutes a stem cell. A minimalist, usually accepted definition of stem cells, is that they must have the capacity of self-renewal and of generating differentiated progeny. ${ }^{10}$ Other properties also associated with stem cells are their ability to survive in a mitotic quiescent form, the capacity to clonally regenerate some or all the different cell types that constitute the tissue in which they exist, and the ability to undergo asymmetric cell divisions. ${ }^{41-43}$

Normal somatic cells have a limited replicative potential. When the so-called 'Hayflick limit' is reached, the cells undergo a viable nongrowing state, known as 'replicative senescence'.11,12,44-46 Cells that have to acquire an extensive self-renewal potential like stem cells need to overcome this growth barrier by activation of telomerase. Low levels of telomerase expression have been described in stem cells of several tissues, namely, in basal cells of the intestinal crypts, basal cells of the skin and hematopoietic progenitor cells, among others. ${ }^{13,45,47}$ Our finding of telomerase expression in the main cells of the solid cell nests provides a new insight on the self-renewal capacity of these cells, characteristic of stem cells in which telomerase has been described to be expressed at very low levels. ${ }^{13,45} \mathrm{We}$ also found scarce and faint expression of telomerase in thyroid follicular cells adjacent to solid cell nests. Other authors using a telomeric repeated amplification protocol (TRAP) assay have already described telomerase activity in normal thyroid. ${ }^{48-52}$ These observations might indicate that follicular cells may have origin in telomerase-positive cells derived from the solid cell nests structure.

Thyroid gland has a very limited proliferative potential. ${ }^{53}$ The results we obtained with the two proliferation markers were very similar and showed that the solid cell nests are composed of low proliferative cells, the positive cells being confined to main cells. The proliferation rate in the cells in the vicinity of solid cell nests was not significantly lower than in the solid cell nests, in contrast to follicular cells distant from solid cell nests in which a significantly lower $(P<0.05)$ proliferation index was found. The higher proliferation rate of the cells of solid cell nests in comparison to that of distant follicular cells, despite its absolute low value, indicates that solid cell nests may constitute a pool of stem cells implicated in the scarce cell division in adult thyroid gland. ${ }^{53}$ The main cells of solid cell nests appear to be slow-growing cells - a feature that fits with the concept that some stem cells exist in a mitotic quiescent form showing low rates of proliferation. ${ }^{10}$ We do not know if the higher proliferation index of the cells in the vicinity of the solid cell nests in comparison to those at a distance from solid cell nests also indicates the involvement of solid cell nests in thyroid cell production, since one cannot rule out the possibility that such a higher proliferation may reflect a reaction to the presence of solid cell nests.

In conclusion, we observed that the main cells of solid cell nests of the thyroid express markers of differentiation potential (p63 and bcl-2 immunoreactivity), self-renewal capability (telomerase activity), and low proliferation rates. All these characteristics are compatible with the usually accepted minimalist definition of stem cells and thus support the assumption that the main cells of solid cell nests may play a stem cell role in the thyroid gland.

\section{Acknowledgements}

We thank Dr Christopher Jones for his help. This study was partially supported by $\mathrm{PhD}$ Grants from the Portuguese Science and Technology Foundation (FCT) (PRAXIS XXI/BD/21795/99 - AP and SFRH/ $\mathrm{BD} / 5386 / 2001$ - JSR-F) with further funding from the same source (POCTI/CBO/41084/2001) - AP and from Gordon Signy International Fellowship Award of the World Pathology Foundations - JSR-F. This work was also supported by Ministerio de Educación y Cultura (PM98-0045) and Xunta de Galicia (PGIDIT03PXIB91801PR), Spain.

\section{References}

1 Cameselle-Teijeiro J, Varela-Durán J, Sambade C, et al. Solid cell nests of the thyroid: light microscopy and immunohistochemical profile. Hum Pathol 1994;25:684-693.

2 Barbareschi M, Pecciarini L, Cangi MG, et al. p63, a p53 homologue, is a selective nuclear marker of myoepithelial cells of the human breast. Am J Surg Pathol 2001;25:1054-1060.

3 Mills AA, Zheng B, Wang XJ, et al. p63 is a p53 homologue required for limb and epidermal morphogenesis. Nature 1999;398:708-713.

4 Yang A, Schweitzer R, Sun D, et al. p63 is essential for regenerative proliferation in limb, craniofacial and epithelial development. Nature 1999;398:714-718.

5 Little NA, Jochemsen AG. p63. Int J Biochem Cell Biol 2002;34:6-9.

6 Reis-Filho JS, Schmitt FC. Taking advantage of basic research: p63 is a reliable myoepithelial and stem cell marker. Adv Anat Pathol 2002;9:280-289.

7 Reis-Filho JS, Torio B, Albergaria A, et al. p63 expression in normal skin and usual cutaneous carcinomas. J Cutan Pathol 2002;29:517-523.

8 Reis-Filho J, Preto A, Soares P, et al. p63 expression in solid cell nests of the thyroid: further evidence for a stem cell origin. Mod Pathol 2003;16:43-48.

9 Lu QL, Abel P, Foster CS, et al. Bcl-2: role in epithelial differentiation and oncogenesis. Hum Pathol 1996;27:102-110.

10 Morrison SJ, Shah NM, Anderson DJ. Regulatory mechanisms in stem cell biology. Cell 1997;88: 287-298. 
11 Hayflick L, Moorhead PS. The serial cultivation of human diploid cell strains. Exp Cell Res 1961;25: 585-621.

12 Hayflick, L. The limited in vitro liftime of human diploid cell strains. Exp Cell Res 1965;37: 614-636.

13 Hiyama K, Hirai Y, Kyoizumi S, et al. Activation of telomerase in human lymphocytes and hematopoietic progenitor cells. J Immunol 1995;155: 3711-3715.

14 Kim NW, Piatyszek MA, Prowse KR, et al. Specific association of human telomerase activity with immortal cells and cancer. Science 1994;266:2011-2015.

15 Bryan TM, Cech TR. Telomerase and the maintenance of chromosome ends. Curr Opin Cell Biol 1999;11: 318-324.

16 Shay JW, Bacchetti S. A survey of telomerase activity in human cancer. Eur J Cancer 1997;33:787-791.

17 Kolquist KA, Ellisen LW, Counter CM, et al. Expression of TERT in early premalignant lesions and a subset of cells in normal tissues. Nat Genet 1998;19:182-186.

18 Vaziri H, Benchimol S. Reconstitution of telomerase activity in normal human cells leads to elongation of telomeres and extended replicative life span. Curr Biol 1998;8:279-282.

19 Jiang XR, Jimenez G, Chang E, et al. Telomerase expression in human somatic cells does not induce changes associated with a transformed phenotype. Nat Genet 1999;21:111-114.

20 Morales CP, Holt SE, Ouellette M, et al. Absence of cancer-associated changes in human fibroblasts immortalized with telomerase. Nat Genet 1999;21: 115-118.

21 Cattoretti G, Becker MH, Key G, et al. Monoclonal antibodies against recombinant parts of the ki-67 antigen (MIB 1 and MIB 3) detect proliferating cells in microwave-processed formalin-fixed paraffin sections. J Pathol 1991;168:357-363.

22 Ishimi Y, Komamura Y, You Z, et al. Biochemical function of mouse minichromosome maintenance 2 protein. J Biol Chem 1998;273:8369-8375.

23 Preto A, Reis-Filho J, Ricardo S, et al. P63 expression in papillary and anaplastic carcinomas of the thyroid gland: lack of an oncogenic role in tumorigenesis and progresion. Pathol Res Pract 2002;198: 449-454.

24 Erdheim JI. Uber Schilddrusenaolasie. II. Geschwulste des Ductus Thyreoglossus. III. Uber einige menschliche Kiemenderivate. Beitr Pathol Anat 1904;35: 366-433.

25 Calver R, Isler H. Fine structure of a third epithelal component of the thyroid gland of the rat. Anat Rec 1970;168:23-41.

26 Kameda Y. Co-expression of vimentin and 19S-thyroglobulin in follicular cells located in the C-cell complex of dog thyroid gland. J Histochem Cytochem 1995;43:1097-1106.

27 Ljungberg O, Nilsson PO. Hyperplastic and neoplastic changes in ultimobranchial remnants and in parafollicular (C) cells in bulls: a histologic and immunohistochemical study. Vet Pathol 1985;22:95-103.

28 Harach HR, Vujanic GM, Jasani B. Ultimobranchial body nests in human fetal thyroid: an autopsy, histological, and immunohistochemical study in relation to solid cell nests and mucoepidermoid carcinoma of the thyroid. J Pathol 1993;169:465-469.
29 Martin V, Martin L, Viennet G, et al. Solid cell nests et pathologies thyroidiennes. Étude retrospective de 1390 thyroides. Ann Pathol 2000;20:196-201.

30 Ozaki O, Ito K, Sugino K, et al. Solid cell nests of the thyroid gland: precursor of mucoepidermoid carcinoma? World J Surg 1992;16:685-689.

31 Cameselle-Teijeiro J. Mucoepidermoid carcinoma and solid cell nests of the thyroid. Hum Pathol 1996; 27:861-863.

32 Cameselle-Teijeiro J, Varela-Durán J. Intrathyroid salivary gland-type tissue in multinodular goiter. Virchows Archiv 1994;425:331-334.

33 Harach HR. Thyroid follicles with acid mucins in man. A second kind of follicles? Cell Tissue Res 1985;242: 211-215.

34 Harach HR. Solid cell nests of the thyroid. J Pathol 1988;155:191-200.

35 Miyauchi A, Matsuzuka F, Kuma K, et al. Piriform sinus fistula and the ultimobranchial body. Histopathology 1992;20:221-227.

36 Pueblitz S, Weinberg AG, Albores-Saavedra J. Thyroid $\mathrm{C}$ cells in the DiGeorge anomaly. A quantitative study. Pediatr Pathol 1993;13:463-473.

37 Pueblitz S. Origins of C cells and follicular cells of the thyroid. Hum Pathol 1995;26:355-356.

38 Williams ED, Toyn CE, Harach HR. The ultimobranchial body and congenital thyroid abnormalities in man. J Pathol 1989;159:135-141.

39 Cameselle-Teijeiro J, Febles-Perez C, Sobrinho-Simoes M. Papillary and mucoepidermoid carcinoma of the thyroid with anaplastic transformation: a case report with histologic and immunohistochemical findings that support a provocative histogenetic hypothesis. Pathol Res Pract 1995;191: 1214-1221.

40 Nagi CS, Unger P, Wang BY, et al. P63-positive cells in solid cell nests (SCNs) and papilary carcinoma of thyroid: evidence for stem-cell regulatory action of p63 in thyroid disorders and neoplasia [abstract]. Mod Pathol 2003;16:480.

41 Hall PA, Watt FM. Stem cells: the generation and maintenance of cellular diversity. Development 1989;106:619-633.

42 Potten CS, Loeffler M. Stem cells: attributes, cycles, spirals, pitfalls and uncertainties. Lessons for and from the crypt. Development 1990;110:1001-1020.

43 Hall PA. What are stem cells and how are they controlled? J Pathol 1989;158:275-277.

44 Mathon NF, Lloyd AC. Cell senescence and cancer. Nat Rev Cancer 2001;1:203-213.

45 Hastie ND, Dempster M, Dunlop MG, et al. Telomere reduction in human colorectal carcinoma and with ageing. Nature 1990;346:866-868.

46 Wynford-Thomas D. Cellular senescence and cancer. J Pathol 1999;187:100-111.

47 Matthews P, Jones CJ. Clinical implications of telomerase detection. Histopathology 2001;38:485-498.

48 Haugen BR, Nawaz S, Markham N, et al. Telomerase activity in benign and malignant thyroid tumors. Thyroid 1997;7:337-342.

49 Yashima K, Vuitch F, Gazdar AF, et al. Telomerase activity in benign and malignant thyroid diseases. Surgery 1997;122:1141-1145.

50 De Deken X, Vilain C, Van Sande J, et al. Decrease of telomere length in thyroid adenomas without telomerase activity. J Clin Endocrinol Metab 1998;83: 4368-4372. 
51 Onoda N, Ishikawa T, Yoshikawa K, et al. Telomerase activity in thyroid tumors. Oncol Rep 1998;5: 1447-1450.

52 Kammori M, Takubo K, Nakamura K, et al. Telomerase activity and telomere length in benign and malignant human thyroid tissues. Cancer Lett 2000;159:175-181.

53 Dumont JE, Maenhaut C, Pirson I, et al. Growth factors controlling the thyroid gland. Baillieres Clin Endocrinol Metab 1991;5:727-754. 